\title{
Impact of Internet of Things (IoT) as Persuasive Technology
}

\author{
Shagufta Faryad \\ Department of Computer Science, COMSATS University Islamabad, Sahiwal Campus, Pakistan \\ E-mail: shaguftafaryad@gmail.com
}

\section{Hira Batool}

Department of Computer Science, COMSATS University Islamabad, Sahiwal Campus, Pakistan

E-mail: hirabatool272@gmail.com

\author{
Muhammad Asif \\ Department of Computer Science and IT, University of Lahore (UOL), Pakistan \\ E-mail: drasifpk@hotmail.com
}

\author{
Affan Yasin \\ School of Software, Tsinghua University, Beijing, P.R.China \\ E-mail: affan.yasin@qq.com
}

Received: 16 August 2021; Accepted: 11 October 2021; Published: 08 December 2021

\begin{abstract}
The Internet of Things (IoT) adds a new dimension to how people and things can communicate and collaborate. Society and the Internet are now being interconnected tightly and purposely. The research aims to analyze how IoT as a persuasive technology can affect human behavior and increase the awareness and effectiveness of IoT products among users. How will the Internet of Things infrastructure facilitate humans to change their attitudes and behaviors towards specific routine work? Our objective is to analyze which factors influence the acceptance and rejection of particular behaviors and the core motivators that persuade people to do something or to avoid something. We aim to determine whether IoT will facilitate humans to change their focused behaviors or not. Because of the rapid convergence of digital and physical worlds and the advent of digital technology, the Internet and social media have opened up a new world of affordances, constraints, and information flows from a design perspective. This article discusses how digital architecture affects behavior and the ramifications for designers who want to influence behavior for social and environmental good. In this paper we aim to give a brief introduction to persuasive technology, especially as it pertains to human adoption of IoT technology. We discuss a number of current research opportunities in IoT gadgets and their adoptions [1]. Our results indicate that persuasive (IoT) infrastructure can be expected to achieve a change of driving behaviour among their adopters. Furthermore, attention should be paid to an appropriate selection and implementation of persuasive strategies.
\end{abstract}

Index Terms: Persuasive Behaviour, Behavioural Changes, User Behaviour, IoT Persuasion, Impact of Persuasion.

\section{Introduction}

Technology makes our life easier, is a statement we all have heard before. In advancing technology, we look for new methods to enhance our lives through technology advancements, inventions, and ideas regularly. In modern human civilization, the concept of a system that allows us to achieve more meaningful life goals with less work has become inspire-able. Although the concept is basic, the term itself offers nearly limitless possibilities for what we might accomplish with technology and how much it can affect our living standards and make our lives easier and more comfortable [2, 3]. All this can be achieved by the concept of (IoT) also called Internet Of Things. It is defined as a concept representing a set of connected services and networks that anyone may use anywhere, at any time. The aim is to provide every connected device the ability to recognize, sense, network, and process with other objects across a network to achieve specific goals $[4,5]$.

Internet of Things (IoT) had significant power to change many aspects of our life. However, how can we ensure that our everyday objects, which are made of smart devices, etc Wearable devices, can change our lives or in-depth saying to what extent? In our world, we have people with different demographics, different life experiences, and facing various problems ranging from health, education, traveling, banking, etc. Persuasive Technologies and the Internet of 
Things in combination are powerful tools that can be used to solve our daily life problems involving a change in behaviour for the betterment of humanity $[6,7]$.

Persuasive technologies [8,9] attempt to form, strengthen or change attitudes, feelings, or thoughts about issues, things, or work. The challenges can be accomplished through software support for carrying out the work, computerhuman dialogue, honest advice, or social influence. Persuasive technologies aim to provide new abilities to make the desired character easier to achieve, help in compelling experiences that effectively attract users, or create relationships with various signs of confidence-building and support the desired change. These technologies are often used by users to maintain a healthy lifestyle, be environmentally friendly, or buy certain products.

\section{A. Motivation and Research Questions}

This work will urge the researchers to explore more critically the influences, impacts and effects of (IoT) implementation that is expected in near future. This study will provide an early review about its impact on human behaviour.

- RQ1: What is the role of Persuasive Technology in adopting devices based on Internet of Things?

1. RQ1.1 What are the factors that influence the acceptance and rejection of specific behaviours?

2. RQ1.2 What are the core motivators that persuade the people to do something or to avoid something?

Rationale: The main aim of the above research questions is to find the role of persuasive technology in adopting wearable / non-wearable devices which are using the concept of (IoT) and analyze the factors that influence the acceptance of some behaviour say $\mathrm{X}$ and explore the reason for rejection of other particular behaviour $\mathrm{Y}$.

- $\quad$ RQ2: Whether (IoT) will facilitate the humans to change their focused behaviours or not.

Rationale: The primary goal of this research question is to see that, will (IoT) be able to alter the behaviour of the person and how this will help in real life for the humans.

\section{B. Internet of Things (IoT)}

The Internet of Things (IoT) means the ever-growing network of physical objects that feature an IP address for internet connectivity, and the communication that occurs between these objects and other Internet-enabled devices and systems. The Internet of Things extends internet connectivity beyond traditional devices like desktop, computers, smart phone's and tablets to a diverse range of devices and everyday things that utilize embedded technology to communicate and interact with the external environment, all via the Internet $[10,11]$. Each object with a unique IP address can find out another object irrespective of its place, time constraint, and type of object. Things having identity can talk to each other. This communication can be between PCs, Human to Human, Human to Machine or Machine to Machine at anywhere at any time irrespective of the physical position of this object. Sensors can be used to sense data and actuators are used to control the mechanism by using some source of energy provided internally or externally to it [12].

Internet of Things not only connects the things it will dominate the overall controlling power. This worldwide network will have a persuasive influence on the normal behaviours of the people for their normal routine tasks. They will be able to exchange, communicate, and to share all kind of information with each other at any place, at any time. The new technologies like RFIDs, sensors networks, actuators, and other persuasive technical models for (IoT) helping to make life more easy, convenient, more flexible and more efficient. (IoT) will able the people they can automate their workstations, their homes, and their cities. The obvious thing is the efficiency of communication in (IoT) Infrastructure. There are many architectures purposed for (IoT) infrastructure e.g. RFIDbased, sensor based and actuator based architectures. We need cloud computing and server-side architectures to connect the devices to a global network [13, $14]$.

\section{Persuasive Technology}

What is Persuasive Technology? Persuasive technology can be explained as following: BJ Fogg defines the Persuasive Technology as "Any interactive computing system designed to change people's attitudes or behaviours" [15, 16]. "Persuasive Technology is the technology intended to promote changes in users' behaviours or attitudes. Persuasive technologies aimed at changing user habit, dried, or character by computer- human dialogue and the social effects $[17,18]$.

Historical Perspective of Persuasive Technology? The study of computer systems as persuasive technologies (called "Captology") was introduced at CHI 97 as a new area of inquiry. A persuasive system is an interactive technology that attempts to change attitudes or behaviours in some way or other. It describes how systems can inherit three types of deliberateness: endogenous, exogenous, and Autogenously [19].

In the last nearly ten years, Persuasion is investigating two clearly distinct lines of research captology, teaching, and persuasion. The former connected to the study of computers as persuasive technologies. The latter having to use 
persuasion as a pedagogical approach to teaching and creating training products (educational software) that encourage students to acquire new knowledge and skills [20].

Fogg's behavioural model: B.J Fogg proposed a behavioural model known as Fogg's Behaviour Model (FBM) to explain the behaviour changes and the factors affecting these behavioural changes.

This above Figure 1 provides a way to visualize the Fogg's behavioural model. FBM has two axes. The vertical axis is for motivation. One person who has low motivation for particular target behaviour will be shown low on the vertical axis. High on the axis means high motivation. The framework is conceptual having no values or units. It displays the relationship between the components. The second $\mathrm{x}$-axis is horizontal, as shown in the figure. This axis is for ability. A person who is on low ability to perform target behaviour would be marked toward the left side of the axis. The right side is for high ability. Both axes define a plane. Target behaviour is represented by the star in the upper right hand. This star is a symbolic representation. It means for a target behaviour to occur both ability and motivation should be high. The arrow that is diagonally extended across the plane from the bottom left to upper right corner elaborate this relationship between motivation, ability and target behaviour. This arrow indicates that as the person increases in his or her ability and motivation, the target behaviour is more likely to be performed [19].

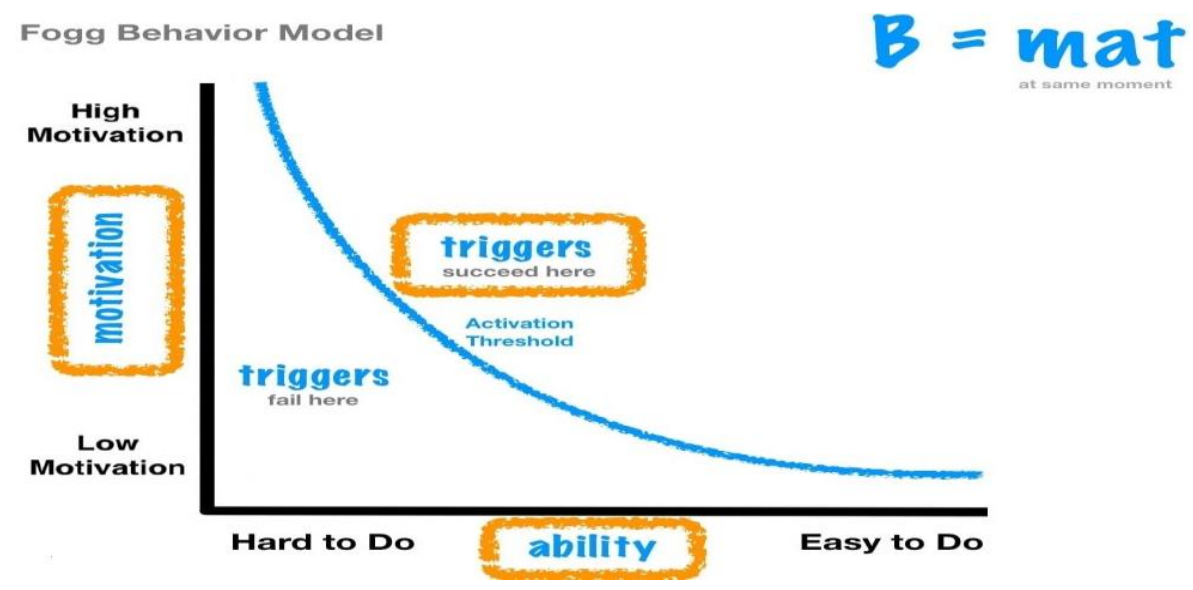

Fig.1. The Fogg's Behavior Model [19]

According to FBM behaviour is an outcome of three input factors: motivation, ability, and triggers, all of the cited factors have sub-components. The FBM justifies that for a person to perform target behaviour, he or she must:-

- Be sufficiently motivated.

- Have the ability to perform the behaviour.

- Be triggered to perform the behaviour.

These three factors must occur at the same moment; else the behaviour will not happen [19].

Many of the people and organizations normally have the concept that the technology changes influence the people's behaviours at some certain levels. It is true, but still there is a need to identify the factors that cause the behavioural changes. So that we can understand how a certain technology can motivate the people to change their behaviours. Persuasive technology is fundamentally about learning to automate behaviour change. To effectively encode experiences that change behaviours, we need to understand human psychology practically as possible, specifically need to elaborate the factors that drive human behaviour $[9,8]$.

Fogg refers three basic factors: Motivation, Ability, and Triggers as shown in the below Figure 2. These play a vital role in behaviour to happen a person must have enough ability, motivation, and effective trigger and also all of these factors must be present at the same time for a particular behaviour to occur. For a specific behaviour to occur high ability and high motivation are required with trigger factor. The ability alone is not enough and the same with motivation. Besides this trigger factor is also critical. These three factors are vital to each other for the occurrence of the target behaviour.

The flow of the research study is as follows: Section II explained the literature review of the research topic; Section III discussed the research methodology, which further explained Personas and Scenario-based approach; Section IV elucidated survey design and how the survey was conducted; Section V discussed the results, and Section VI concludes and further explain the answers to the research questions. 


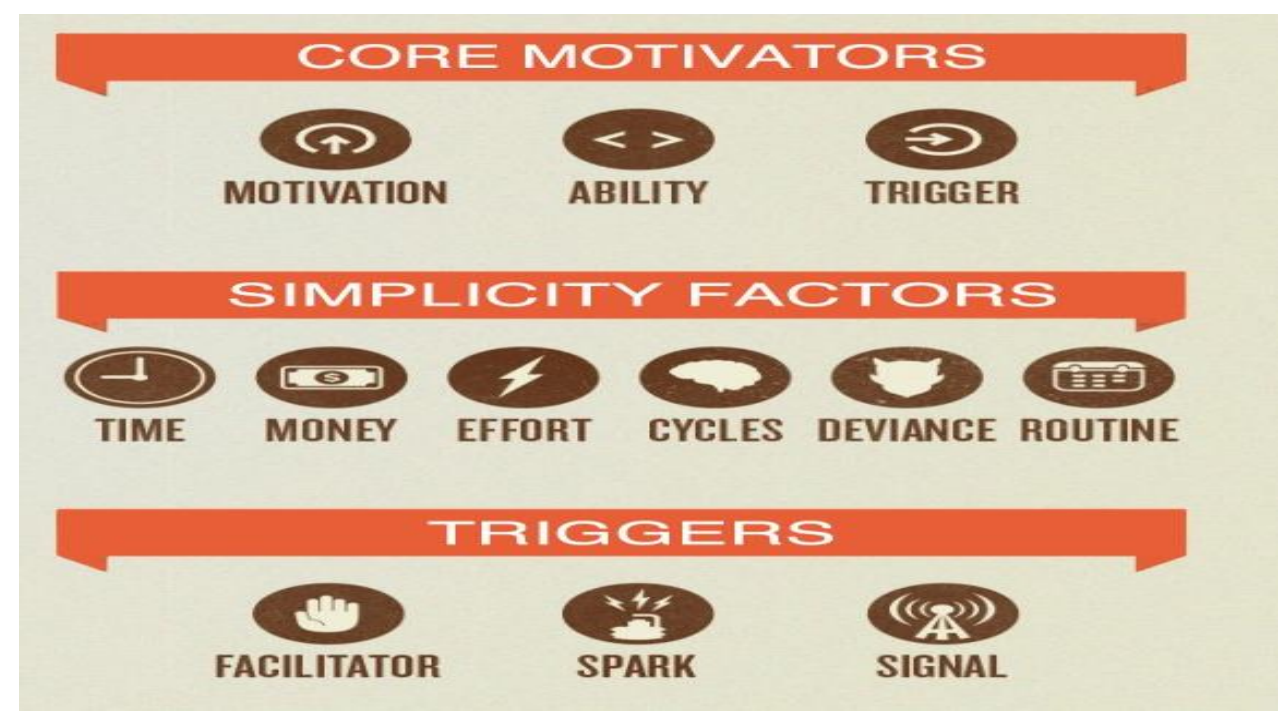

Fig.2. The Fogg's Behavior Model Explanation [19]

\section{Related Work}

IoT in Health-Care: IoT is used in healthcare systems to acquire and analyze vast amounts of healthcare data by utilizing adaptability, cost reduction, flexibility, and high-speed features. Because it gives artificial intelligence agents and humans more autonomy to collaborate and resolve issues, the currently operational CMDS (cooperative medical diagnosis multi-agent system) can address a wide range of medical diagnosis problems [21].

IoT devices help not only medical facilities and patients but also healthy individuals. IoT health devices might play a role in giving bodily health information, goal suggestions, diet progress monitoring, and timetable milestones by offering more transparent information. IoT devices used in healthcare include Health trackers, such as built-in applications and arm-bands. These devices help individuals record, plan, manage continuously, and perform specific actions to achieve health-related goals [22].

IoT in Wearable: In wearable items, the IoT is continuously introducing new devices with new technology and features in the market that can gather, analyze, and transmit data. Such devices include sport watches equipped with GPS technology, facial recognition, security cameras, smart houses, intelligent toothbrush, and many more. The demand and use of these devices have increased rapidly in the past few years [23].

These IoT devices provide various conveniences to their users, but they can also compromise users' privacy without their knowledge. The purpose of these wearable gadgets is to provide entertainment and to improve one's quality of life. Wearable devices are electronics or computers that may be integrated into clothes and accessories and worn on the body. Smart clothing, smart motorcycle helmets, smart bracelets, and smart eyewear are examples of wearable technologies. Wearable gadgets were once primarily utilized in the military, but they are now being used in various sectors, including gaming, agriculture, health, and more [24, 25].

Wearable gadgets capture a large quantity of data and create a variety of privacy issues. It is unclear to the user where all of this information is going to and what is being done with this data, where it is used, or who is gathering this data. Nonetheless, most businesses use them in the workplace, generating a slew of societal problems. Although wearable devices might put users' privacy at risk, these gadgets provide advantages for both employers and people. As a result, there is always a trade-off between the hazards of using such technology and the apparent advantages[26].

IoT in Agriculture: The Industrial Internet of Things (IoT) has already impacted industries, including agriculture. The worldwide connected agricultural industry was of a value of billion dollars at the end of 2018, and it is still growing. IoT has made different wearable devices, linked gadgets, automated machinery, and autonomous automobiles in their usage [27].

IoT is helping out in issues such as early detection of harsh weather, climatic changes, and environmental effect; furthermore, it is helping in meeting the continuous supply of food for the growing population. Due to the continuously increasing need for food, the agriculture industry relies significantly on creative concepts. One of the challenges may be the behavioral intentions to adopt these changes and move on from traditional concepts [6].

\section{Factors Effecting Behavioral Intention to Use IoT}

- Ethics: Every person's behavioral goals and privacy concerns about IoT devices are unique. To better understand a person's behavioral purpose, an understanding of ethical or moral behavior is necessary. Ethical or moral conduct can relate to a wide range of actions; nevertheless, this behavior is dependent on human perceptions, which might change from one person to the other and from time to time. Individuals concerned 
about privacy and security are likely to be concerned about challenges associated with IoT technology [28, 29, 30]. As a result, their behavioral intention to utilize IoT devices might be negatively impacted.

- Trust On Technology: Another critical factor that affects human behavior towards IoT is trust, as users' beliefs influence their intentions. The more trust in a device or technology is, the more the user starts adopting it.

- Risk: Risk is another important factor that affects the human intention and behavior against adopting the IoT technology. Risk is a feeling of apprehension about the possibility of undesirable outcomes when utilizing a product or service [31].

- Perceived Usefulness [32]: Perceived usefulness is another essential factor affecting human behavior against IoT. It is defined as the person's desire or will to use the technology. The more valuable IoT devices are seen to be, the more likely the person will adopt. Behavioral intentions are also significantly influenced by perceived ease of use and perceived utility.

\section{Research Methodology}

The scenario-based approach $[18,33]$ is used for this research work. "Scenarios deal with the world of facts and the world of perceptions. They explore for facts, but they aim at perceptions inside the heads of decision-makers." [34]. "The most important purpose of the scenario building process is to shift the thinking of the leadership of the organization about what might happen, in the future, in the external environment" [35].

Persona is the imaginary person/user in each scenario. Scenarios describe a particular situation. Personas are used to explain scenarios $[36,37]$.

\section{A. Personas}

Persona of Diabetic patient: Mr.Sahil is 45 years old. He is a business dealer as well as a general manager, in Tariq Ayyub Charted Accountants Co. He is a married person having two children of 15 and eight years old. He is living very busy life with lots of business meetings and visiting tours. Due to malnutrition domestic and professional worries, he is suffering from diabetes since he was 42 years old. As he loves to eat desserts and sweets his blood sugar level goes high. Now he needs to control his blood glucose level and also blood pressure. He needs to take the best care of his health and have such food as healthy and useful for his healthy life.

Persona of Obesity patient: Mr.Yousaf is 28 years old. He is a software engineer at Rosen Feed Co. He lives in a hotel. He is fond of fast food, e.g., pizza, burger Etc. He has much-sitting work and projects. He is too busy to take exercises regularly. He cannot go for jogging because of his busy schedule that does not let him go for it. However, this is much important to keep him active and fit. So, day by day he is gaining extra fats on his body and losing his charming look and doesn't seem handsome anymore. He is becoming obese, and much worried about his physical fitness and look. Now he wants to control his obesity and become fit and active again. So he needs to take proper exercises and go for jogging that is necessary to burn his body fats.

Persona of smart toothbrush: Mr. Ali is eight years old. He is a student at Young Scholar School. He is a lover of sweets and chocolates. His teeth are much affected because he does not take an interest in brushing his teeth and always made lame excuses to avoid brushing as it is boring duty for him. As a result food particles remain in his mouth and cause cavities now, it is a big problem to make tooth brushing interesting for Ali to keep his teeth strong and clean.

\section{B. Scenarios}

\section{Scenario for Smart Heart Beat Monitoring Gadget:}

Mr. Farhan wearing his smart heartbeat monitoring gadget is going back to is home after the tiring workload of the University. He is feeling mush disturbed and tired. While driving the car, he is thinking about his wife who is admitted to hospital for last five days and no caring hands is waiting for him there. She is not pretty fine and needs more care. After covering some miles, he stops driving and gets out of his car with a pack of cigars. He is standing alone at the roadside and start smoking. Smart gadget fixed in his arm starts monitoring the rate of his heartbeat consistently also providing him current heartbeat rate through a generating message on his cell phone. As soon he will finish six cigars and go for next one, gadget trace the heartbeat rate and send a message to him as a precautionary measure. However, he does not put attention towards this message. Now, gadget again sends him a message that generates an alarm in the voice of her wife. Suddenly, when he listens to her wife's voice, he stops smoking and takes a long breath. He has stopped smoking and turn back to complete his journey. In this way, (IoT) as persuasive technology motivates him to change his behaviour.

Scenario for smart toothbrush: Today is Sunday and Ali does not have to go to school. His mother comes in his room and says to him: "Good Morning Son! Wake Up!" It is time to take breakfast so be fresh and ready for it. However, Ali was thinking that today I will not brush my teeth, feeling a big task to brush teeth as doing this annoying task for two minutes. However, when he goes to the washroom, he saw a new "HasBro" brush saying hello to him. He picks it and start looking it. Attractive design urges him to use it. Ali places toothpaste on it and starts brushing. When he uses it for the first time, he moves brush to and fro; its vibrating bristles produce sound in his ears. Ali listens that sound and tries 
again. He likes this sound and start enjoying with brushing. In this way, he regularly brushes his teeth for more than 2 minutes while enjoying music. This new HasBro brush changed her attitude towards brushing her teeth. It motivates him to take care of his teeth. This is the smart brush that can communicate with Ali using RFID tag.

Scenario for Obesity Monitoring Smart Gadget: Now a day’s Mr.Yousaf is living in a world of (IoT). He is wearing a smart device that can monitor its body calories level and communicate with him. It motivates him to take exercise regularly and go for jogging as he starts running on the track the device starts communicating with him and tells him some of the calories he burnt during jogging. Also, provide him guidance about the diet having fewer amounts of calories. As Mr.Yousaf was needed to control his obesity, and he can do this, but he was quite lazy and have no motivation, but smart device motivates him to manage his routine in such a way that he could be able of having some time for his exercises to change his lazy behaviour towards his fitness. Now he has started to take regular exercises and jogging.

Scenario for Smart Diabetes Monitoring Gadget: Today, Mr.Sahil is invited to reception ceremony of his friend. That is why he is in an excellent mood. After 12'o'clock, he goes for a business deal and return with great success. This makes him happier, and now he is feeling quite hungry. His watch sends him a message that it is time to attend his friend's reception ceremony. That was exactly the time to go for the ceremony. He dressed well and reached there. There were multiple dishes enriched with sugar and oil. However, he was starved, he meets his friend say congrats, and then they turn for a heavy lunch. He takes meal and when he touches the pots of sweets, these starts communicating with his gadget and informs him about the sugar amount that these are containing, gadget send him a voice message that his blood sugar level is about — and he can consume - amount of sugar more. After listening to it, he decides that he will not eat dessert. Now, he is fit and feeling relax, not hungry. In this way, gadget motivates him to control himself from more eating to avoid diabetes.

\section{Survey Design}

There are many ways to conduct research and collect information such as; Interview, data extracted from the online source, survey Etc; A survey is defined as a brief interview or discussion with individuals about a particular topic. Nowadays, Surveys are one of the most critical basic research methods in the social sciences and an important tool in many other disciplines. That is the main reason we have selected Survey as our research methodology.

\section{A. Study Design \& Process}

In-Person Surveys: In person survey is one of the methods which is most helpful in collecting survey data efficiently, and we have followed this methodology [32]. The respondents are comfortable in front of the researcher, as the researcher can explain the questions which may arise while filling the survey. One of the researchers was presented during filing of the survey and more than $90 \%$ of the data was attained by using In-Person Survey methodology.

Google forms: Google form is also used to collect the questionnaire data online and for initial analysis. We receive a good number of responses, but still the results may be limited due to time limitation, publicity, hindrance or incapability of using computer or incapability to fill.

Response Rate: The survey link was active from 1st November 2015 and closed on 30th November 2015. The response rate is more than $85 \%$, as the majority of the data is collected by using In-Person survey methodology.

Behaviour - Identity protection: To make them feel comfortable, we categorically state in In-person survey and Online survey forms that:-

- The respondents have the right to fill or not to fill the questionnaire.

\section{Education}

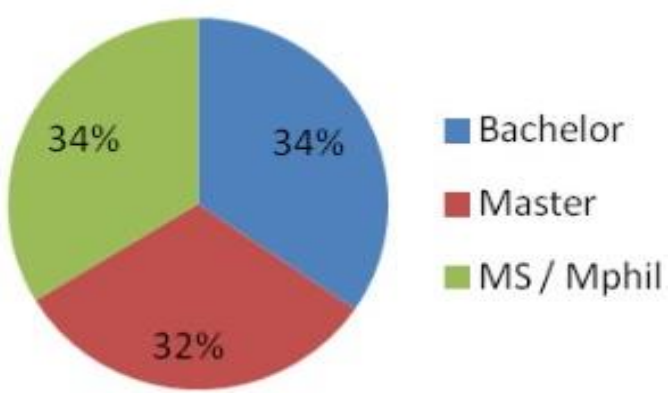

Fig.3. Education Distribution of Participants 


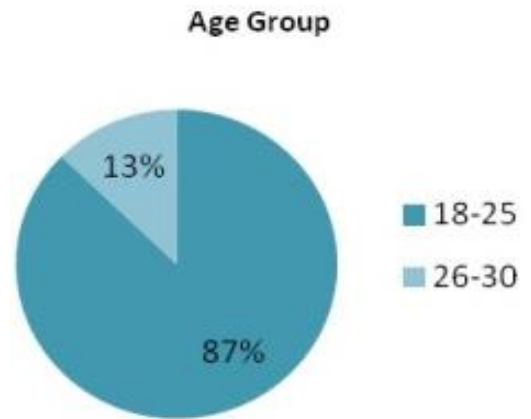

(a) Age Distribution

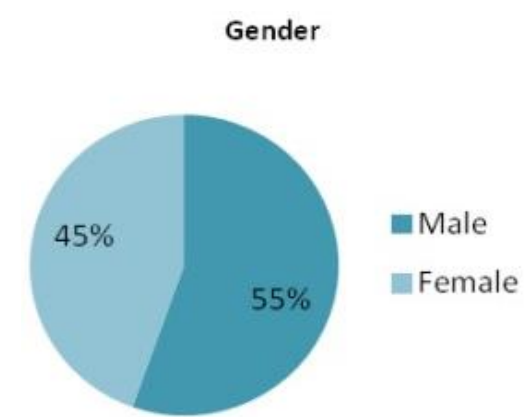

(b) Gender Distribution

Fig.4. Age and Gender Distribution of Participants

- The identity of the person who will fill the survey will not be disclosed, and only the researchers or authorized persons will have the access to the respondent's data.

Pilot Survey \& Trust Evaluation [38] After completing Identity protection process, a pilot survey was performed on the participants of the University of Pakistan. We have performed a pilot test of the survey. For the pilot test we circulated and got the data from 10 respondents, mostly our colleagues and friends. The results obtained from the pilot survey were used to predict how our actual results will look like, and we used the initial result of pilot survey to add and delete the survey questions. The pilot survey response shows people were satisfied with our stance and explanation on data protection and usage.

Data Filtering We have tried to filter the data by putting certain checks on the data.

- Firstly, Respondent who has filled survey multiple times is removed from the database.

- Secondly, respondents selected all maximum scale in a survey or selected all minimum scale in the survey was removed. There are chances that someone has filled the survey for the sake of filling or filled survey without reading the questions completely.

Respondents Sample and Characteristics There were three sections of the survey, the first section contains the demographics related questions, the second section contains survey questions on particular scenarios, and the third section contains mix questions related to all scenarios and overall experience of respondents. The details of survey respondents are given below:-

- The resulting sample comprised of 100+ final responses. In Figure 4a above, we have explained the gender distribution of the respondents. Gender distribution is almost balanced with $55 \%$ of the respondents being male and $45 \%$ female.

- As explained in the above Figure $4 \mathrm{~b}, 87 \%$ of respondents were within age group $18-25$, and $13 \%$ of respondents were within the age group 26-30, which indicates a bias towards younger people.

As explained in the above Figure 3, 34\% of respondents were of MS / MPhil students, 34\% belong to bachelor, and $32 \%$ belong to Master, which indicates the survey respondents are well-educated people.

\section{Results}

As explained in the Figure 5 below are the findings:

- Survey Question 1 (Explained in Appendix): 56\% of respondents agree, and 27\% of them strongly agree with the fact that calories monitoring system can motivate Mr.Yousaf for having more exercises, which indicates a good number of people believe that this system will be helpful in changing behaviour of an individual.

- Survey Question 2 (Explained in Appendix): 49\% of respondents agree, and 36\% of them strongly agree with the fact that calories monitoring system can help Mr.Yousaf to manage his time to take exercise, which indicates a good number of people believe that this system will be helpful in changing behaviour of Mr. Yousaf.

- Survey Question 3 (Explained in Appendix): 49\% of respondents, agree, and 25\% of them strongly agree with the fact that calories monitoring system can help Mr.Yousaf to maintain some of the calories.

- Survey Question 4 (Explained in Appendix): $42 \%$ of respondents agree and $44 \%$ of them strongly agree with the fact that Mr.Yousaf will get the real time information of his burning rate of calories. 
As explained in the above Figure 6, below are the findings:

- $\quad$ Survey Question 5 (Explained in Appendix): 48\% of respondents agree, and 41\% of them strongly agree with the fact that by using Diabetes monitoring gadget Mr.Farhan will be able to control his glucose level.

- Survey Question 6 (Explained in Appendix): 55\% of respondents agree, and 31\% of them strongly agree with the fact that Diabetes monitoring gadget can guide Mr.Farhan on his diet.

Survey Question 7 (Explained in Appendix): 48\% of respondents agree, and 34\% of them strongly agree with the fact that Diabetes monitoring gadget will be able to stop Mr.Farhan from eating dessert.

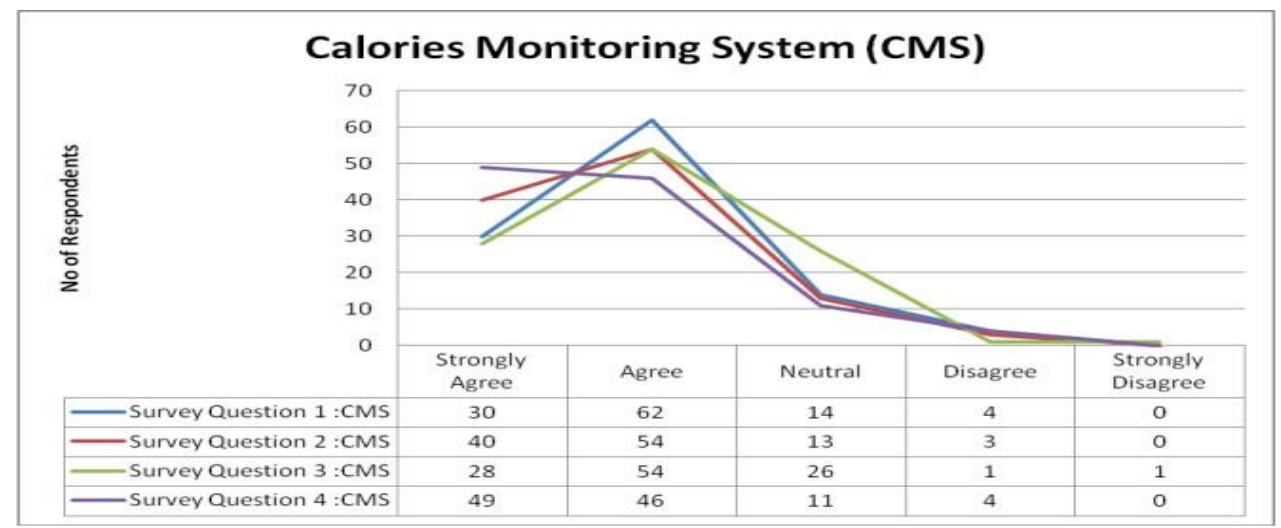

Fig.5. Survey Questions - CMS

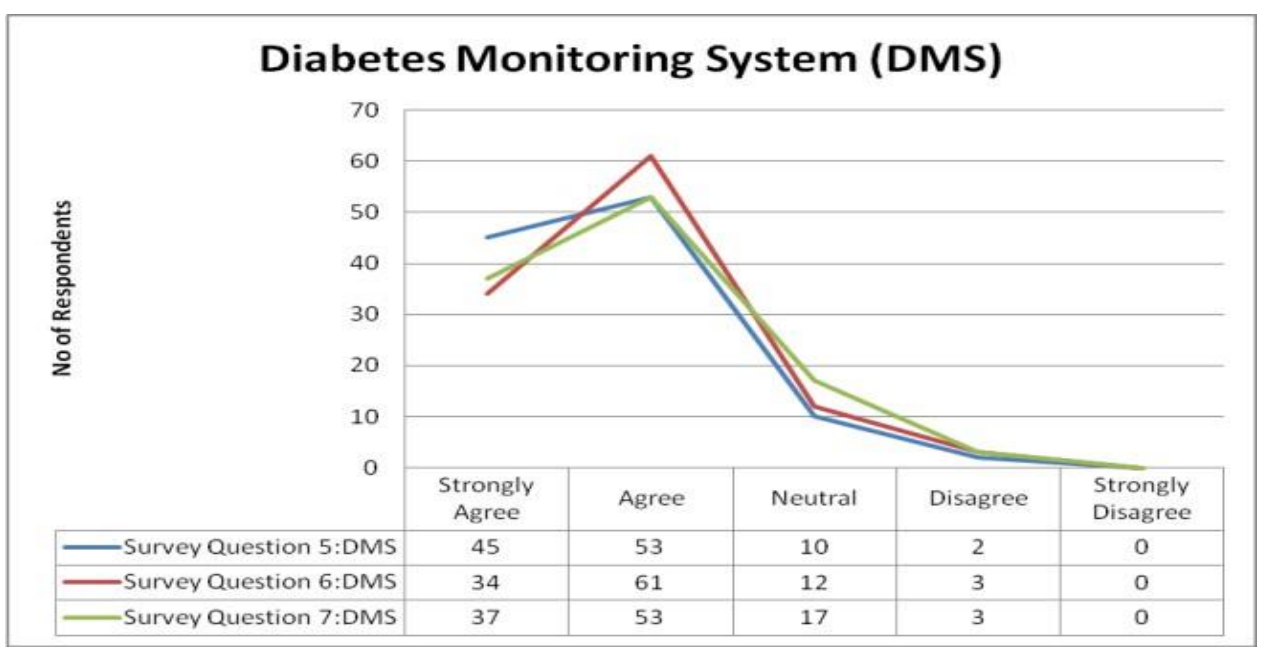

Fig.6. Survey Questions - DMS

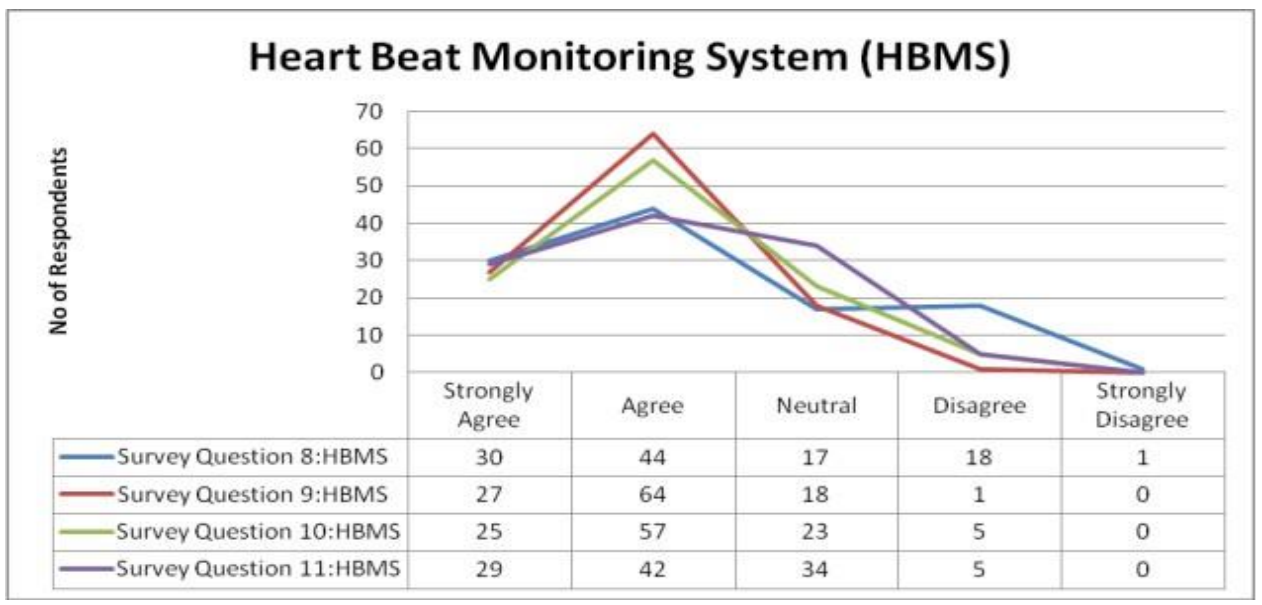

Fig.7. Survey Questions - HBMS 


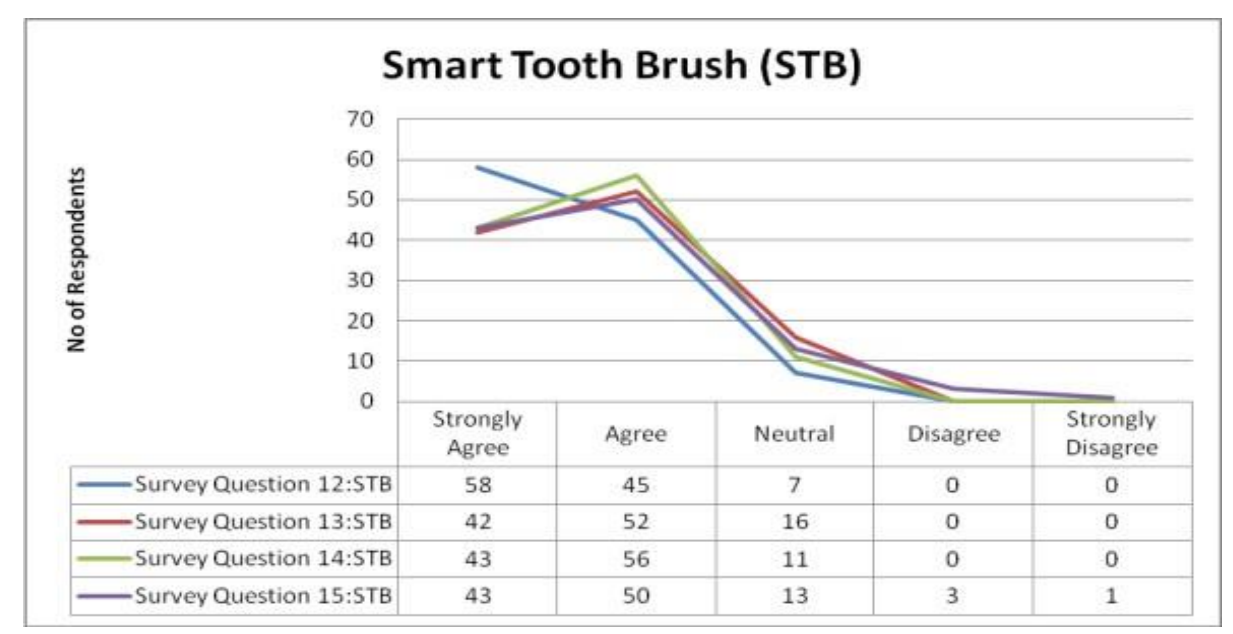

Fig.8. Survey Questions - STB

As explained in the above Figure 7, below are the findings:

- $\quad$ Survey Question 8 (Explained in Appendix): 40\% of respondents, agree, and 27\% of them strongly agree with the fact that instant message from Mr.Sahil's wife can help to stop smoking.

- Survey Question 9 (Explained in Appendix): 58\% of respondents agree, and 25\% of them strongly agree with the fact that Heartbeat monitoring system can help Mr.Sahil's to monitor the continuous variations in the heart beat.

- Survey Question 10 (Explained in Appendix): 52\% of respondents, agree, and 23\% of them strongly agree with the fact that Heartbeat monitoring system can be a care-taker for Mr.Sahil's for controlling his smoking habit.

- Survey Question 11 (Explained in Appendix): 38\% of respondents agree, and 26\% of them strongly agree with the fact that Heartbeat monitoring system can be helpful for Mr.Sahil's for quitting his smoking habit.

As explained in the Figure 8, below are the findings:

- $\quad$ Survey Question 12 (Explained in Appendix): 41\% of respondents agree, and 53\% of them strongly agree with the fact that Smart toothbrush will be attractive for a child Ali.

- $\quad$ Survey Question 13 (Explained in Appendix): 47\% of respondents agree, and 38\% of them strongly agree with the fact that Smart toothbrush will motivate a child Ali for brushing.

- Survey Question 14 (Explained in Appendix): 51\% of respondents agree, and 39\% of them strongly agree with the fact that Ali will enjoy brushing while music is playing from the toothbrush.

- Survey Question 15 (Explained in Appendix): 45\% of respondents, agree, and 39\% of them strongly agree with the fact that smart toothbrush will help Ali to regulate 2 minutes brushing.

This study reports the initial findings, and there is still a need to extend and verify the results at a large scale. The external validity of the study is still to be verified.

\section{Conclusions}

With recent advancements in internet technologies, the Internet Of Things (IoT) is beginning to significantly influence our daily lives and offer fascinating and beneficial new services. However, in a world with significant issues like demographic shift, rising depression, and many other concerns related to human health, it is imperative that we responsibly use the IoT and act very smart in its use to avoid various effects. IoT devices have much effect on human psychology and can also affect human behavior in several ways.

The starting point of this paper was the observation that Internet of Things can be used as persuasive technology, which is intended to influence human behaviour, summarized in the following by answering the research questions raised at the beginning of this paper. It is now evident that statement proposed at the start that behavioural changes are caused by certain factors such as motivation, ability, and triggers are true.

Overall, the four scenarios that constitute the proposed persuasive (IoT) Infrastructure achieved a moderately positive acceptance level. The strongest factor to influence the intention to adopt the proposed infrastructure was Performance, Ease of Use, and assistance. Social persuasion indicates that gender moderates the influence of Social Influence such that men are more influenced by their social environment than women, whereas assistance matters as a fact for humans as (IoT) infrastructure can be used to assist them to make their life healthier. Importance - the degree to 
which a person feels a certain need to get the proposed assistance - increases the influence of Performance. Personal Relevance, which measures an individual's devotion and interest in the studied domain, has turned out to have a large effect. Consequently, our results indicate that persuasive (IoT) infrastructure can be expected to achieve a change of driving behaviour among their adopters. Furthermore, attention should be paid to an appropriate selection and implementation of persuasive strategies. This study has explored various challenges and weaknesses of (IoT) technology use, especially as they continue to pervade everyday life. From the results of the study, it is evident that, while the (IoT) will make life easier, and persuade people to change their behaviours.

\section{Acknowledgment}

We would like to express our appreciation to all those who have supported us during our research and study.

\section{References}

[1] Dan Lockton. Persuasive technology and digital design for behaviour change. Available at SSRN 2125957, 2012.

[2] Richard C Dorf. Technology, humans, and society: toward a sustainable world. Elsevier, 2001.

[3] RC Michelini and RP Razzoli. Product-service eco-design: knowledge-based infrastructures. Journal of Cleaner Production, 12(4):415-428, 2004.

[4] Nina Cvar, Jure Trilar, Andrej Kos, Mojca Volk, and Emilija Stojmenova Duh. The use of iot technology in smart cities and smart villages: Similarities, differences, and future prospects. Sensors, 20(14):3897, 2020.

[5] Ali Nauman, Yazdan Ahmad Qadri, Muhammad Amjad, Yousaf Bin Zikria, Muhammad Khalil Afzal, and Sung Won Kim. Multimedia internet of things: A comprehensive survey. IEEE Access, 8:8202-8250, 2020.

[6] Sandro Nižetic, Petar Šoli' c, Diego López-de-Ipiña González-' de, Luigi Patrono, et al. Internet of things (iot): Opportunities, issues and challenges towards a smart and sustainable future. Journal of Cleaner Production, 274:122877, 2020.

[7] Seelam Vasavi Sai Viswanada Prabhu Deva Kumar, Shyam Akashe,"Implementation of GSM Based Security System with IOT Applications", International Journal of Computer Network and Information Security(IJCNIS), Vol.9, No.6, pp.13-20, 2017.DOI 10.5815/ijcnis.2017.06.02

[8] Brian J Fogg. A behavior model for persuasive design. In Proceedings of the 4th international Conference on Persuasive Technology, pages 1-7, 2009.

[9] Brian J Fogg. Persuasive technology: using computers to change what we think and do. Ubiquity, 2002(December):2, 2002.

[10] Daming Li, Lianbing Deng, Wenjian Liu, and Qinglang Su. Improving communication precision of iot through behaviorbased learning in smart city environment. Future Generation Computer Systems, 108:512-520, 2020.

[11] Felix Wortmann and Kristina Flüchter. Internet of things. Business \& Information Systems Engineering, 57(3):221-224, 2015.

[12] Shadi Al-Sarawi, Mohammed Anbar, Kamal Alieyan, and Mahmood Alzubaidi. Internet of things (iot) communication protocols. In 2017 8th International conference on information technology (ICIT), pages 685-690. IEEE, 2017.

[13] Alireza Souri, Aseel Hussien, Mahdi Hoseyninezhad, and Monire Norouzi. A systematic review of iot communication strategies for an efficient smart environment. Transactions on Emerging Telecommunications Technologies, page e3736, 2019.

[14] Joan Melià-Seguí and Rafael Pous. Human-object interaction reasoning using rfid-enabled smart shelf. In 4th International Conference on the Internet of Things, IOT 2014, Cambridge, MA, USA, October 6-8, 2014, pages 37-42. IEEE, 2014.

[15] Harri Oinas-Kukkonen, Khin Than Win, Evangelos Karapanos, Pasi Karppinen, and Eleni A. Kyza, editors. Persuasive Technology: Development of Persuasive and Behavior Change Support Systems - 14th International Conference, PERSUASIVE 2019, Limassol, Cyprus, April 9-11, 2019, Proceedings, volume 11433 of Lecture Notes in Computer Science. Springer, 2019.

[16] Odji Ebenezer. Influencing children: Limitations of the computer-human-interactive persuasive systems in developing societies. International Journal of Modern Education \& Computer Science, 12(5), 2020.

[17] Hiroaki Kimura, Jun Ebisui, Yoshio Funabashi, Akihito Yoshii, and Tatsuo Nakajima. idetective: a persuasive application to motivate healthier behavior using smart phone. In William C. Chu, W. Eric Wong, Mathew J. Palakal, and ChihCheng Hung, editors, Proceedings of the 2011 ACM Symposium on Applied Computing (SAC), TaiChung, Taiwan, March 21 - 24, 2011 , pages 399-404. ACM, 2011.

[18] Rubia Fatima, Affan Yasin, Lin Liu, and Jianmin Wang. How persuasive is a phishing email? A phishing game for phishing awareness. J. Comput. Secur., 27(6):581-612, 2019.

[19] B. J. Fogg. A behavior model for persuasive design. In Samir Chatterjee and Parvati Dev, editors, Persuasive Technology, Fourth International Conference, PERSUASIVE 2009, Claremont, California, USA, April 26-29, 2009. Proceedings, volume 350 of ACM International Conference Proceeding Series, page 40. ACM, 2009.

[20] B. J. Fogg and Jason Hreha. Behavior wizard: A method for matching target behaviors with solutions. In Thomas Ploug, Per F. V. Hasle, and Harri Oinas-Kukkonen, editors, Persuasive Technology, 5th International Conference, PERSUASIVE 2010, Copenhagen, Denmark, June 7-10, 2010. Proceedings, volume 6137 of Lecture Notes in Computer Science, pages 117-131. Springer, 2010.

[21] Mostafa Haghi Kashani, Mona Madanipour, Mohammad Nikravan, Parvaneh Asghari, and Ebrahim Mahdipour. A systematic review of iot in healthcare: Applications, techniques, and trends. Journal of Network and Computer Applications, page 103164, 2021.

[22] Sureshkumar Selvaraj and Suresh Sundaravaradhan. Challenges and opportunities in iot healthcare systems: a systematic review. SN Applied Sciences, 2(1):1-8, 2020.

[23] Vaidik Bhatt and Samyadip Chakraborty. Importance of trust in iot based wearable device adoption by patient: An empirical investigation. In 2020 Fourth International Conference on ISMAC (IoT in Social, Mobile, Analytics and Cloud)(I-SMAC), 
pages 1226-1231. IEEE, 2020.

[24] Aleksandr Ometov, Viktoriia Shubina, Lucie Klus, Justyna Skibinska, Salwa Saafi, Pavel Pascacio, Laura Flueratoru,' Darwin Quezada Gaibor, Nadezhda Chukhno, Olga Chukhno, et al. A survey on wearable technology: History, state-of-theart and current challenges. Computer Networks, 193:108074, 2021.

[25] Ming-Zheng Li, Su-Ting Han, and Ye Zhou. Recent advances in flexible field-effect transistors toward wearable sensors. Advanced Intelligent Systems, 2(11):2000113, 2020.

[26] T Poongodi, Rajalakshmi Krishnamurthi, R Indrakumari, P Suresh, and Balamurugan Balusamy. Wearable devices and iot. In A handbook of Internet of Things in biomedical and cyber physical system, pages 245-273. Springer, 2020.

[27] Rajasshrie Pillai and Brijesh Sivathanu. Adoption of internet of things (iot) in the agriculture industry deploying the brt framework. Benchmarking: An International Journal, 2020.

[28] Rubia Fatima, Affan Yasin, Lin Liu, Jianmin Wang, Wasif Afzal, and Awaid Yasin. Sharing information online rationally: An observation of user privacy concerns and awareness using serious game. J. Inf. Secur. Appl., 48, 2019.

[29] Jiska Classen. Security and Privacy for IoT Ecosystems. PhD thesis, Darmstadt University of Technology, Germany, 2020.

[30] Jörg Daubert, Alexander Wiesmaier, and Panayotis Kikiras. A view on privacy \& trust in iot. In IEEE International Conference on Communication, ICC 2015, London, United Kingdom, June 8-12, 2015, Workshop Proceedings, pages 2665- 2670. IEEE, 2015.

[31] Kim-Kwang Raymond Choo, Keke Gai, Luca Chiaraviglio, and Qing Yang. A multidisciplinary approach to internet of things (iot) cybersecurity and risk management. Comput. Secur., 102:102136, 2021.

[32] Affan Yasin, Lin Liu, Tong Li, Jianmin Wang, and Didar Zowghi. Design and preliminary evaluation of a cyber security requirements education game (SREG). Inf. Softw. Technol., 95:179-200, 2018.

[33] Abraham Bernstein, Peter Vorburger, and Patrice Egger. A scenario-based approach for direct interruptability prediction on wearable devices. Int. J. Pervasive Comput. Commun., 3(4):426-438, 2007.

[34] Thomas J. Chermack and Laura M. Coons. Scenario planning: Pierre wack's hidden messages. Futures, 73:187-193, 2015.

[35] T.J. Chermack and L. van der Merwe. The role of constructivist learning in scenario planning. Futures, 35(5):445-460, 2003.

[36] Jane Billestrup, Jan Stage, Anders Bruun, Lene Nielsen, and Kira Storgaard Nielsen. Creating and using personas in software development: Experiences from practice. In Stefan Sauer, Cristian Bogdan, Peter Forbrig, Regina Bernhaupt, and Marco Winckler, editors, Human-Centered Software Engineering - 5th IFIP WG 13.2 International Conference, HCSE 2014, Paderborn, Germany, September 16-18, 2014. Proceedings, volume 8742 of Lecture Notes in Computer Science, pages 251258. Springer, 2014.

[37] Jukka Haikara. Usability in agile software development: Extending the interaction design process with personas approach. In Giulio Concas, Ernesto Damiani, Marco Scotto, and Giancarlo Succi, editors, Agile Processes in Software Engineering and Extreme Programming, 8th International Conference, XP 2007, Como, Italy, June 18-22, 2007, Proceedings, volume 4536 of Lecture Notes in Computer Science, pages 153-156. Springer, 2007.

[38] Mahfida Amjad, Nusrat Jahan Linda. "A Web Based Automated Tool for Course Teacher Evaluation System (TTE)", International Journal of Education and Management Engineering(IJEME), Vol.10, No.2, pp.11-19, 2020.DOI: 10.5815/ijeme.2020.02.02

\section{Appendix A: Questionnaire}

Table 1 further shows the Questionnaire distributed among respondents.

The Figures $9 \& 10$ show the detail of user's responses to various miscellaneous survey questions. If we analyze the above graphs, we can observe that our results indicate that persuasive IoT infrastructure can be expected to achieve a change of driving behaviour among their adopters.

Table 1. Questionnaire

\begin{tabular}{|c|c|c|c|}
\hline Sr.No & Questions & $\begin{array}{l}\text { Factors behind the } \\
\text { Behavioral Change }\end{array}$ & Scenario \\
\hline 1 & $\begin{array}{l}\text { The calories monitoring system can motivate Mr.Yousaf for } \\
\text { having more \& more exercises and jogging. }\end{array}$ & Motivation & \multirow{4}{*}{$\begin{array}{l}\text { Calories } \\
\text { Monitoring } \\
\text { System }\end{array}$} \\
\hline 2 & $\begin{array}{l}\text { The calories surveillance system can help Mr.Yousaf to manage his } \\
\text { time to take exercise. }\end{array}$ & Ability & \\
\hline 3 & $\begin{array}{l}\text { Mr.Yousaf can enjoy the food having a minimum amount of } \\
\text { calories with the direction of calories monitoring system. }\end{array}$ & Ability & \\
\hline 4 & $\begin{array}{l}\text { The message generated by the calories monitoring system can } \\
\text { help Mr.Yousaf having real-time information about burning rate } \\
\text { of calories. }\end{array}$ & Trigger (Reminder) & \\
\hline 5 & $\begin{array}{l}\text { Diabetes monitoring gadget can help Mr.Farhan in controlling body } \\
\text { glucose level. }\end{array}$ & Ability & \multirow{3}{*}{$\begin{array}{l}\text { Diabetes } \\
\text { Monitoring } \\
\text { System }\end{array}$} \\
\hline 6 & Diabetes monitoring gadget can provide guidance about his diet. & Motivation & \\
\hline 7 & $\begin{array}{l}\text { The message generated from diabetes monitoring gadget can help Mr.Farhan to } \\
\text { stop eating desserts. }\end{array}$ & Trigger & \\
\hline
\end{tabular}


Table 1. Continue

\begin{tabular}{|c|c|c|c|}
\hline 8 & An immediate message from Mr.Sahil's wife can help to stop smoking. & Trigger & \multirow{4}{*}{$\begin{array}{l}\text { Heart Beat } \\
\text { Monitoring System. }\end{array}$} \\
\hline 9 & $\begin{array}{l}\text { Heartbeat monitoring system can help Mr.Sahil to monitor the continuous variations } \\
\text { in the heart beat. }\end{array}$ & Motivation & \\
\hline 10 & $\begin{array}{l}\text { Heart beat monitoring system can be a caretaker for Mr. Sahil to control his } \\
\text { smoking. }\end{array}$ & Ability & \\
\hline 11 & The heart beat monitoring system can help Mr.Sahil to stop smoking gradually. & Motivation & \\
\hline 12 & The getting smarter toothbrush seems attractive to Ali. & Motivation & $\begin{array}{l}\text { Smart Tooth } \\
\text { Brush }\end{array}$ \\
\hline 13 & The smart brush can motivate (persuade) Ali. & Motivation & \multirow{17}{*}{$\begin{array}{c}\text { General Questions } \\
\text { Related to all } \\
\text { Scenarios }\end{array}$} \\
\hline 14 & $\begin{array}{l}\text { The smart brush can help to make brushing enjoyable while } \\
\text { listening music. }\end{array}$ & Motivation & \\
\hline 15 & The smart brush can help Ali to regulate 2 minutes brushing. & Ability & \\
\hline 16 & $\begin{array}{l}\text { Friends and family impressed to hear about the usage of such kind of } \\
\text { smart gadgets. }\end{array}$ & Motivation & \\
\hline 17 & $\begin{array}{l}\text { Friends and family would be interested in using such kind of smart } \\
\text { product. }\end{array}$ & Motivation & \\
\hline 18 & $\begin{array}{l}\text { The usage of such kind of smart gadgets magnifies the impression of } \\
\text { their users among their friends and family. }\end{array}$ & Motivation & \\
\hline 19 & User's friends and family would like to have such kind of smart gadgets. & Motivation & \\
\hline 20 & User's friends and family would like to use the IoT technology. & Motivation & \\
\hline 21 & The IoT technology helps to regulate livings towards a particular behavior. & Ability & \\
\hline 22 & The presented concept of smart gadgets is attractive for their users. & Motivation & \\
\hline 23 & The IoT technology is useful for promoting a healthy life. & Motivation & \\
\hline 24 & Smart gadgets are easy to wear. & Ability & \\
\hline 25 & All the smart gadgets presented in the scenarios are user-friendly. & Ability & \\
\hline 26 & All the smart gadgets presented in the scenarios are easy to use. & Motivation, Ability & \\
\hline 27 & All the smart gadgets presented in the scenarios are easy to communicate. & Trigger & \\
\hline 28 & Using smart IoT gadgets and devices would be amazing. & Motivation & \\
\hline 29 & Would you like to live with IoT and use this technology? & Motivation & \\
\hline
\end{tabular}

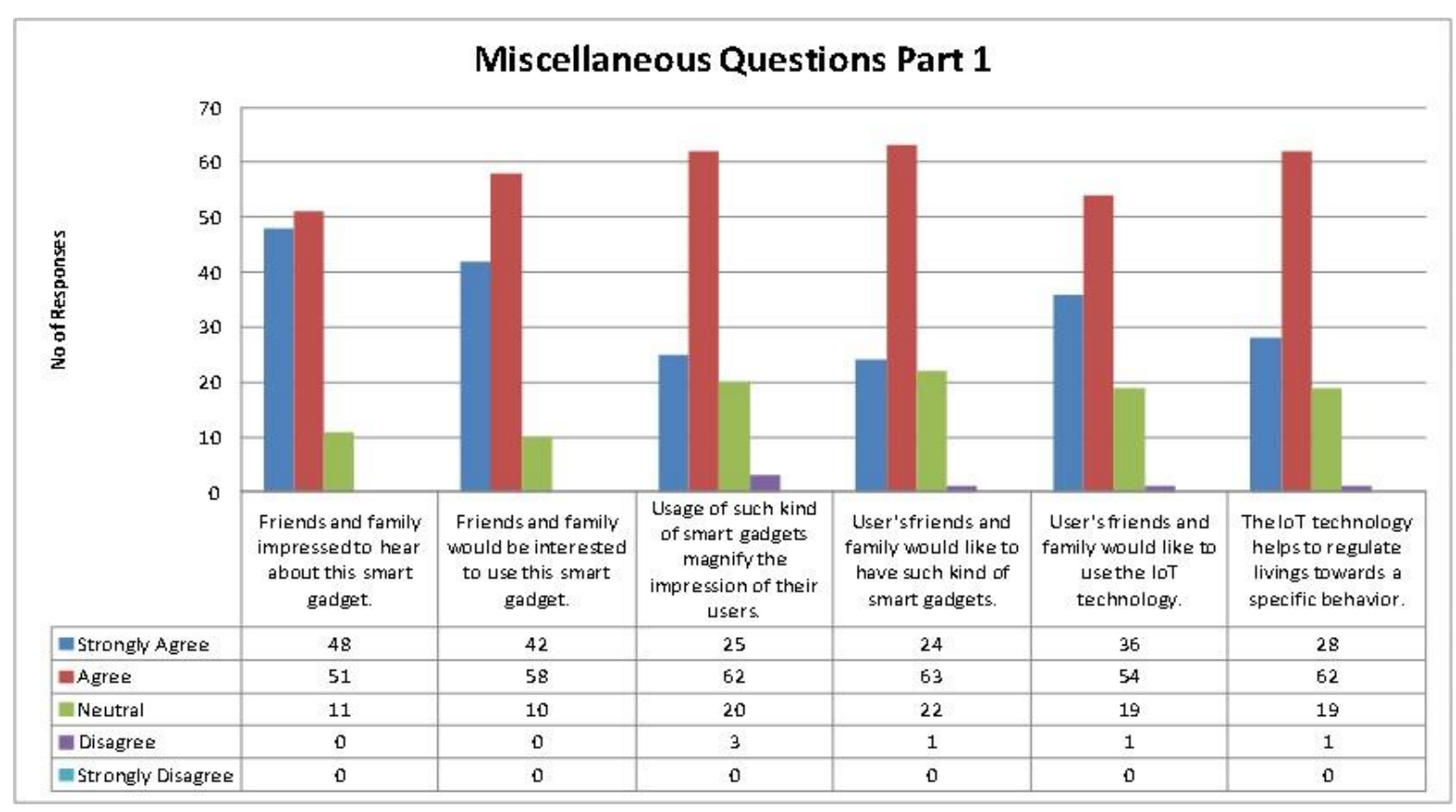

Fig.9. Miscellaneous Questions 1-MQP1 


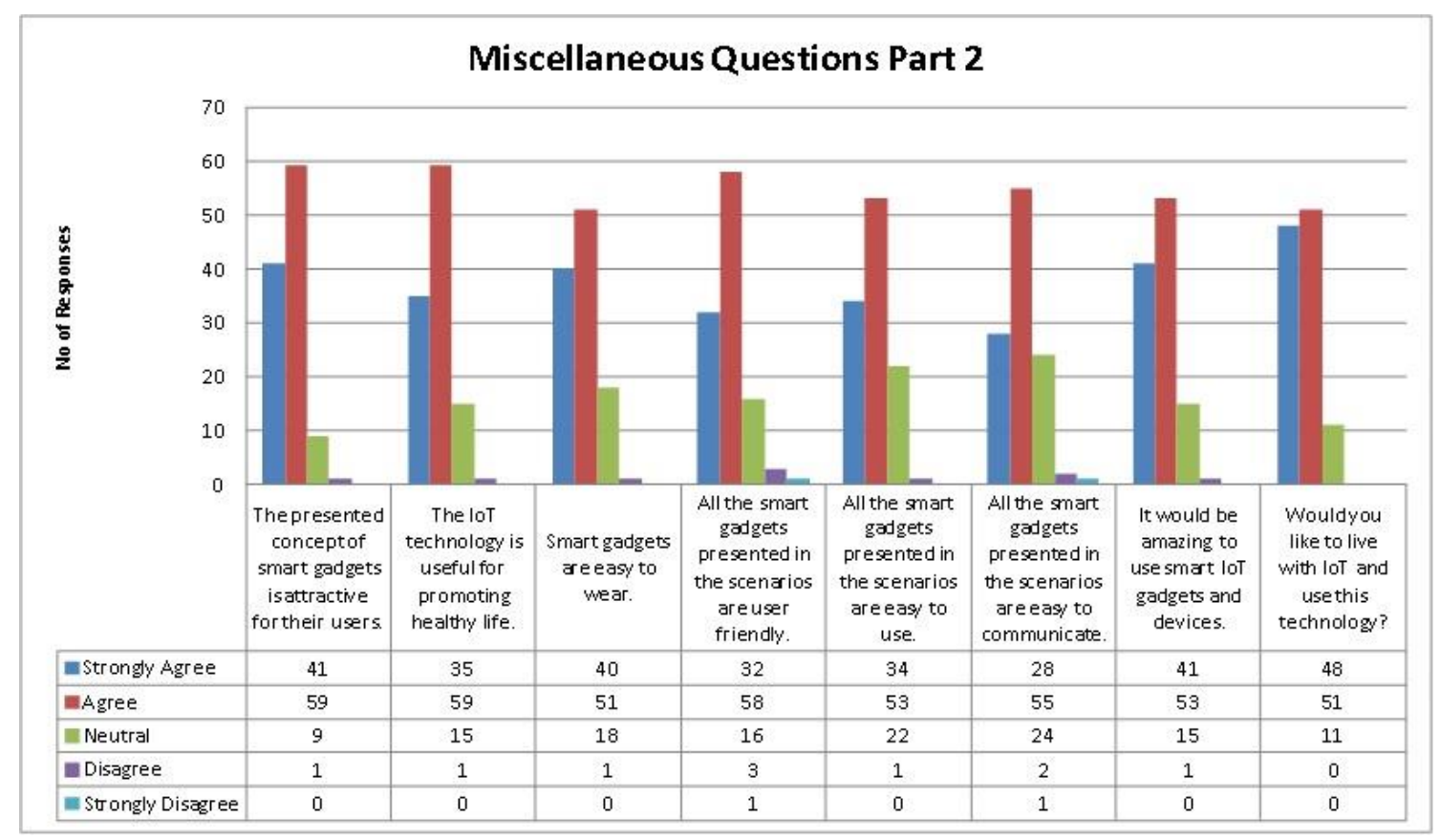

Fig.10. Miscellaneous Questions 2-MQP2

\section{Authors' Profiles}

Ms. Shagufta Faryad has received her Master in Computer Science degree from COMSATS University, Islamabad, Pakistan. Since 2016, she has been CTI (College Teacher Internee) in GPGC Sahiwal, Punjab and currently she is working as an Elementary School Teacher (IT) in SED Punjab, Pakistan. Her areas of interest in research are Internet of things (IoT), persuasive technologies and their relationship with human behaviours.

Ms. Hira Batool has received her Master of Science in Computer Science from COMSATS University, Islamabad, Pakistan. She is working as Secondary School Educator in School Education Deptt. Punjab, Pakistan. Her interests in research are Internet of Things, Human behaviours and Technology.

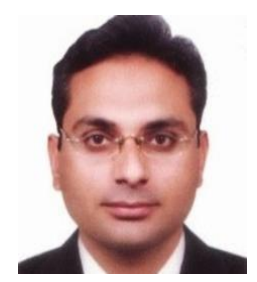

Dr. Muhammad Asif has received his $\mathrm{PhD}$ in Computer Science from the department of computer and information science (IDI), Norwegian University of Science and Technology (NTNU), Norway. Currently, he is working as an Associate Professor in Department of Computer Science, University of Lahore, Pakistan. His research interests are Internet of Things, Mobile Information Systems and Data Sciences

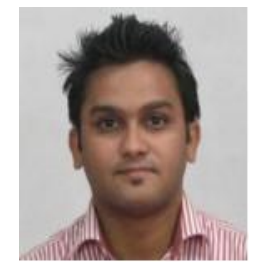

Affan Yasin has received his Bachelor of Science in Computer Science (BSCS) from National University of Computer, and Emerging Sciences (NUCES-FAST), Lahore, Pakistan, and he has received his Master of Science in Software Engineering (MSSE) degree from Blekinge Tekniska Högskola (BTH), Karlskrona, Sweden. Recently, he has completed his Ph.D. from Tsinghua University, Beijing, P.R.China. His area of interest includes empirical research and development within Software Engineering, game-based learning, social engineering, serious game, Persuasive technology and requirements engineering. Currently, he is working as a Post-Doctoral researcher at Tsinghua University, Beijing, P.R.China

How to cite this paper: Shagufta Faryad, Hira Batool, Muhammad Asif, Affan Yasin, "Impact of Internet of Things (IoT) as Persuasive Technology", International Journal of Information Technology and Computer Science(IJITCS), Vol.13, No.6, pp.16-28, 2021. DOI: $10.5815 /$ ijitcs.2021.06.02 